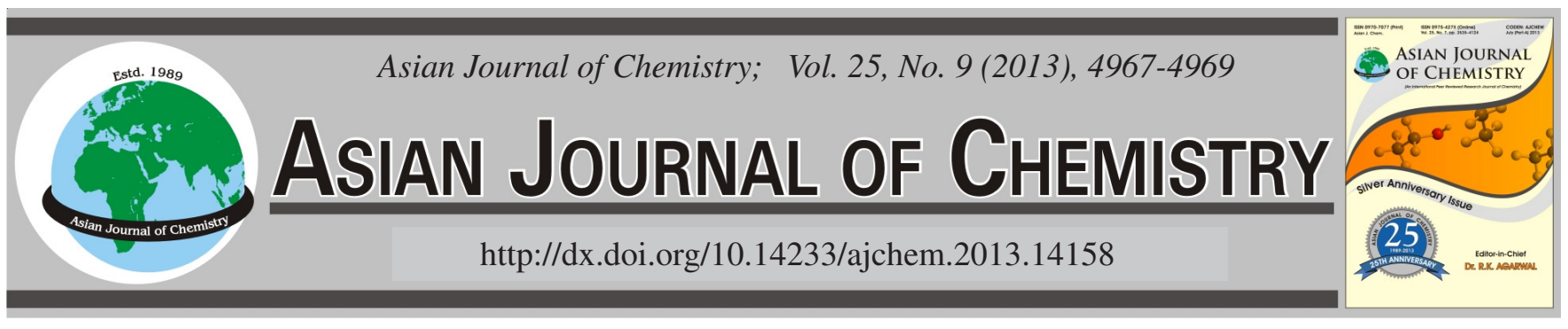

\title{
Rapid Determination of Phenolic Compounds in Extracts of the Leaves of Ipomoea batatas (L.) Lam. by HPLC-DAD-ESI-MS
}

\author{
FAN QiU, ${ }^{1, *}$, YubaO CUI ${ }^{2}$ and Mei JuAN WanG ${ }^{3}$
}

\begin{abstract}
${ }^{1}$ Department of Pharmacy, Yancheng Medical College, 263\# Jiefang Road, Yancheng 224005, Jiangsu Province, P.R. China ${ }^{2}$ Department of Medical Examination, Yancheng Medical College, 263\# Jiefang road, Yancheng 224005, Jiangsu Province, P.R. China ${ }^{3}$ Yancheng Institute for Durg Control, 127\# Jianjun East Road, Yancheng 224002, Jiangsu Province, P.R. China
\end{abstract}

*Corresponding author: E-mail: echo_qf@163.com

\begin{abstract}
Ipomoea batatas (L.) Lam. (Sweet potato) is not only used as staple food, but also is a traditional herbal drug in China for the treatment of various disease. For analyze the component of the extraction, we have developed a chromatography electrospray ionization tandem mass spectrometry (HPLC-ESI-MS/MS) method to characterize th fraction of ethyl acetate, which gtave prominent [M-H] ions by electrospray ionization menitored in the negative ion mode. A total of ten phenolic compounds were identified or tentatively characterized based on the UV spectra and Tandem mass spectra of the HPLC peaks. The tandem mass spectrometric fragmentation behaviour of caffeoylqinic acid derivatives and flavonoids have been investigated extensively.
\end{abstract}

Key Words: Sweet potatoes, Phenols, HPLC-DAD-ESI-MS.

\section{INTRODUCTION}

The sweet potato (Ipomoea batatas) is a dicotyledonous plant which belongs to the family Convolvulaceae. It represents an important crop in tropical, subtropical and warm temperature regions with its agronomic and nutritional advantages ${ }^{1}$. The storage root of sweet potato are used as staple food, raw material for alcohol production and animal feed, while in China, the leaves of sweet potato are a common side dish in cuisine and used as a traditional medicine for a long history. They poach the leaves and drink the water to cure various diseases such as the inflammation of the throat, ascites, diarrhea and astriction.

Sweet potato has long attracted attention for its content of potentially bioactive phytochemicals, including secondary metabolic products. It has been known to contain chlorgenic acid, several caffeoylquinic acids, dicaffeoylquinic acids and flavonoids ${ }^{2-4}$. These phytochemicals have been claimed to possess many pharmacological properties such as antioxidant $t^{5,6}$, anticancer, antiviral and antimicrobial effects ${ }^{7}$, antimutagenicity antidiabetes; anti $\mathrm{HIV}^{8}$, but there have been few studies on the leaves of the plant grown in China to expound the material basement of the activity.

In this paper, a rapid method for determination of the phenolic compounds in the Ipomoea batatas Lam. was described by HPLC/DAD/ESI-MS ${ }^{\mathrm{n}}$ (High-performance liqud chromatography with diode-array detection in parallel with electrospary ionization and ion trap Tandem mass spectrometry). Tne compounds were identified or tentatively characterized, including flavonoids and quinic acid derivatives and the ESI-MS fragmentation behaviour of these compounds was also investigated.

\section{EXPERIMENTAL}

The dry leaves of sweet potato were purchased from local market near Yancheng City in China. All solvents used for extraction were of analytical grade (Hanbon Sci \& Tech, Jiangsu, China), methanol used for HPLC were of chromatographic grade (Hambon Sci \& Tech, Jiangsu, China) and water used was distilled water. Acetic acid used were of analytical grade (Nanjing Chemical Reagent Co. Ltd.)

Extraction and isolation: One hundred grams of dry leaves of sweet potato was extracted with $1 \mathrm{~L} 95 \%$ ethanol and then evaporated to form a syrup. The syrup was dissolfed in $300 \mathrm{~mL}$ of water by sonication and paritioned with chloroform and ethyl acetate of equal volume three times successively, the ethyl acetate solution was vacuum evaporated at $65^{\circ} \mathrm{C}$. About $2.5 \mathrm{~g}$ residue of ethyl acetate was obtained. The residues was dissolved with methanol and filtered through a $0.45 \mu \mathrm{m}$ filer for HPLC analysis.

HPLC condition: The analysis were performed using an Agilent series 1100 HPLC instrument (Agilent, Waldbronn, Germany) equipped with a quaternary pump, a diode-array 
detector (DAD), an autosampler and a column compartment. The sample was separated on Welch XB-C ${ }_{18}(250 \mathrm{~mm} \times 4.6$ $\mathrm{mm}, 5 \mu \mathrm{m})$. the mobile phase consisted of water containing $0.1 \%(\mathrm{~V} / \mathrm{V})$ acetic acid (A) and methanol (B) ith a gradient from $25 \%(\mathrm{~V} / \mathrm{V}) \mathrm{B}$ to $35 \%(\mathrm{~V} / \mathrm{V}) \mathrm{B}$ in the first $15 \mathrm{~min}$, then from $40-45 \%$ over $20 \mathrm{~min}$ and then to $50 \%(\mathrm{~V} / \mathrm{V}) \mathrm{B}$ over $10 \mathrm{~min}$. The mobile phase flow rate was $1.0 \mathrm{~mL} / \mathrm{min}$, and the column temperature was set at $25^{\circ} \mathrm{C}$. The DAD was set to monitor at $255 \mathrm{~nm}$ and the on-line UV spectra were recorded in the range $190-400 \mathrm{~nm}$.

Mass spectrometry: For HPLC/MS analysis, Agilent 1100 Series LC/MSD Trap SL was connected to the HPLC instrument via an ESI interface. Ultahigh-purity helium $(\mathrm{He})$ was used as the collosion gas purity nitrogen $\left(\mathrm{N}_{2}\right)$ as the nebulizing gas. The ionization parameters in the negative ion mode were as follows, dry temp: 350 , Nebulizer: 45.00 psi, dry gas: $10.00 \mathrm{~L} / \mathrm{min}$, HV Capillary: $3000 \mathrm{~V}$. for full-scan MS analysis, the spectra were recorded in the range $\mathrm{m} / \mathrm{z}$ 50-1000. Datadependent acquisition was used so that the two most abundant ions in each MS scan were selected in turn and subjected to tandem mass spectrometry analysis. the collision energy for CID was adjusted to $35 \%$ of maximum.

\section{RESULTS AND DISCUSSION}

A detailed study of the fragmentation pattern of the caffeates and flavonoids from sweet potato was made employing triple quadrupole mass analyzers. In this way, the mass fragmentation behaviour could be analyzed in terms of the potential applied. Most consituents displayed a similar spectral behavour with two maximum absorption peaks at 220-250 and 320-330 $\mathrm{nm}$ and a shoulder at 290-300 nm (Table-1). They were characterized as hydroxycinnamic acid derivatives ${ }^{9}$. Some peaks corresponding to flavones (three absorption peaks around 250, 280 and $350 \mathrm{~nm}$ ) were also observed. HPLC/MS was utilized for further characterized of individual substances. Druing HPLC/MS analysis, a key step was to determine the molecular weight of each component analyzed. Usually, the most abundant peak in a full MS spectrum was assigned as $[\mathrm{M}-\mathrm{H}]^{-}$and if adduct ions $\left([\mathrm{M}-\mathrm{H}+\mathrm{HCOOH}]^{-}\right)$and dimers could be observed, this assignment was more solid. The typical chromatogram of an extract of the leaves of sweet potato is shown in Fig. 1, while Table-1 shows the retention times, UV absorptions, MS and $\mathrm{MS}^{2}$ spectral data and identification results for the peaks in the chromatogram.

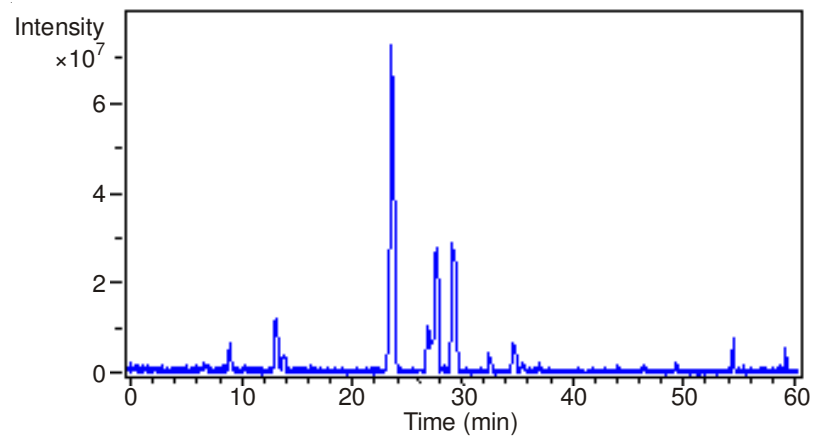

Fig. 1. LC-negative ion ESI-MS total ion current (TIC) profile

Two parent ions at $\mathrm{m} / \mathrm{z} 353$ were detected at the elution time 9.3 and 10.5 min they were characterized by $\mathrm{UV}^{10}$ and mass spectra as caffeoylquinic acid. They yielded a $[\mathrm{M}-\mathrm{M}]^{-}$ ion at $\mathrm{m} / \mathrm{z} 173$, indicating the sequential loss of water. They were 3-acyl, 4-acyl or 5-acyl isomers of caffeoylquinic acid, with 5-caffeoylquinic acid dominant ${ }^{11}$ and its chemical structures was shown in Fig. 2.

Compound 3 yield a $[\mathrm{M}-\mathrm{H}]^{-}$at $\mathrm{m} / \mathrm{z} 179$, it only loses the neutral molecule $\mathrm{CO}_{2}$, giving the anion of $\mathrm{m} / \mathrm{z} 135$, because the hemolytic cleavage of benzylic bond it relatively rare with an electrospray ionization source. It was identified as caffeic $\operatorname{acid}^{12}$.

Four peaks at m/z 515 were characterized as di-Ocaffeoylquinic acids (CQAs) isomers. they all shown the loss of $162 \mathrm{u}$, the caffeoyl group, to provide a very clear ion at $\mathrm{m} / \mathrm{z} 353$. A second loss of $162 \mathrm{u}$ produces the $\mathrm{m} / \mathrm{z} 191$ ion, which represents the intact quinic acid function. The loss of two neutral species with a mass of $162 \mathrm{u}$ identifies the ester functions as being the same and to be caffeic acid. Because the presence of mixed ester group will, therefore, be indicated by the sequential loss of one acidic group, followed by expulsion

TABLE-1

CHROMATOGRAPHIC, UV AND SPECTRAL CHARACTERISTICS OF PHENOLIC COMPOUNDS FROM CHINESE SWEET POTATO LEAVES

\begin{tabular}{|c|c|c|c|c|c|}
\hline $\begin{array}{l}\text { Comp. } \\
\text { No. }\end{array}$ & $\begin{array}{l}\text { Retention time } \\
\quad(\min )\end{array}$ & $\mathrm{UV} \lambda_{\max }(\mathrm{nm})$ & $\begin{array}{l}{[\mathrm{M}-\mathrm{H}]} \\
(\mathrm{m} / \mathrm{z})\end{array}$ & HPLC-ESI-MS ${ }^{\mathrm{a}} \mathrm{m} / \mathrm{z}$ & Identification \\
\hline $\begin{array}{l}1 \\
2\end{array}$ & $\begin{array}{c}9.3 \\
10.5\end{array}$ & $220,302 \operatorname{sh}, 328$ & 353 & $\begin{array}{l}\operatorname{MS}^{2}[353]: 191,179 \\
\operatorname{MS}^{3}[191]: 173\end{array}$ & Caffeoylquinic acid \\
\hline 3 & 13.1 & 217,297 & 179 & $\mathrm{MS}^{2}[179]: 135$ & Caffeic acid \\
\hline 4 & 23.1 & $217,242,297,326$ & 515 & 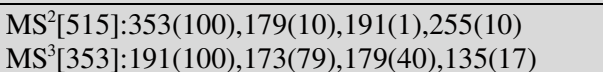 & 1,3-diCQA \\
\hline 5 & 24.0 & & & $\begin{array}{l}\operatorname{MS}^{2}[515]: 353(100), 179(1), 173(12), 300(9), 335(9) \\
\operatorname{MS}^{3}[353]: 191(100), 173(20), 179(35), 135(1)\end{array}$ & 1,4-diCQA \\
\hline 6 & 28.9 & & & $\begin{array}{l}\operatorname{MS}^{2}[515]: 353(100), 179(8), 255(2), 173(7) \\
\operatorname{MS}^{3}[353]: 179(100), 173(61), 179(8), 190(23)\end{array}$ & 3,4-diCQA \\
\hline 7 & 29.7 & & & $\begin{array}{l}\operatorname{MS}^{2}[515]: 353(100), 173(5), 335(4) \\
\operatorname{MS}^{3}[353]: 173(100), 179(4), 135(74)\end{array}$ & 3,5-diCQA \\
\hline 8 & 27.0 & $254,295,355$ & 463 & $\begin{array}{l}\operatorname{MS}^{2}[463]: 301,302 \\
\operatorname{MS}^{3}[301]: 255,107,151,179,271\end{array}$ & Quercetin-3-glucoside \\
\hline 9 & 32.0 & 350,255 & 447 & $\begin{array}{l}\text { MS }^{2}[447]: 285,284,255 \\
\text { MS }^{3}[285]: 257,107,155,227,285\end{array}$ & $\begin{array}{l}\text { Kaempferol-3-O- } \\
\text { glucoside }\end{array}$ \\
\hline 10 & 46.2 & 255,370 & 301 & $\operatorname{MS}^{2}[301]: 151$ & Quercetin \\
\hline
\end{tabular}




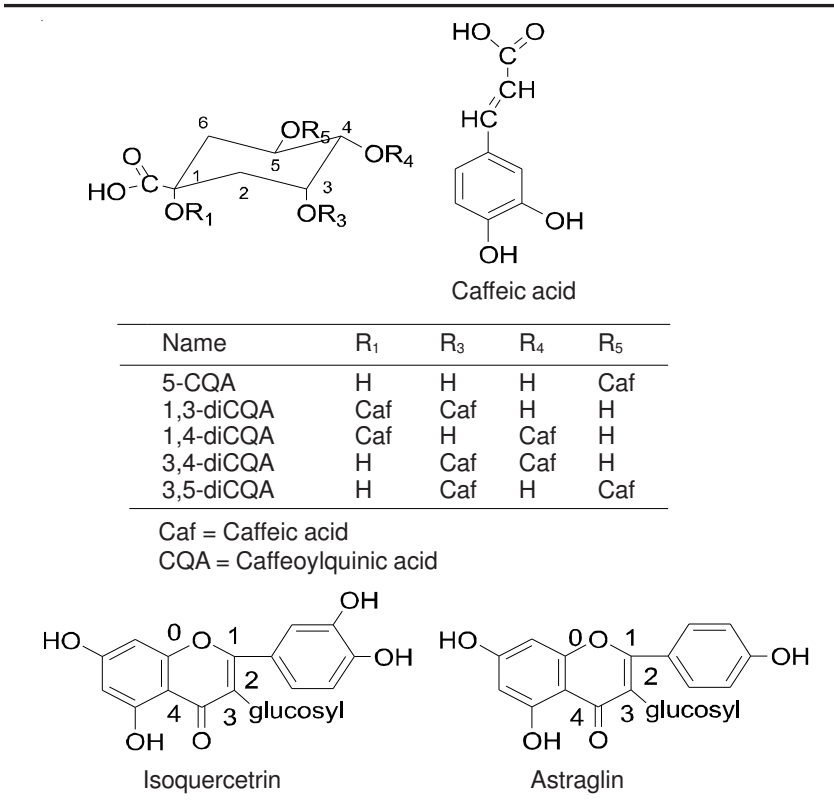

Fig. 2. Main chemical structures of compounds identified from the leaves of sweet potato

of the second functionality and the spectrum would contain two ions in the mid-range of the spectrum, one for each of the acidic groups. The $\mathrm{m} / \mathrm{z} 191$ ion also give rise to peaks at $\mathrm{m} / \mathrm{z}$ 173 by the loss of molecules of water. The peaks at m/z 179 ion, the acid of the ester with an intact carboxyl group, which carries a negative charge easily; if a mixed ester were being analyzed, two different ions ould be observed which would identify the mass of each acid functionality. In the present case, both ester are identical and only one ion is observed. The fragments at m/z 135 are fomred by the loss of $\mathrm{CO}_{2}$ from the carboxylic acids, such processes are known to occur in aromatic carboxylic acids ${ }^{13}$. For diCQA, the ease of removal of the caffeoyl residue during fragmentation is $1 \approx 5>3>4$, which was one of the reasons for the diversity of the intense of the peaks in mass spectra. The four isomers was discriminated by using the hierarchical key established by Clifford and co-workers ${ }^{14}$ and comparison of retention time, elution order on reversed-phase packing ${ }^{15}$. They were identified as 1,3-diCQA, 1,4-diCQA, 3,4-diCQA, 3,5-diCQA directly.

The peak at m/z 463 [M-1] $]^{-}, \mathrm{m} / \mathrm{z} 447$ [M-1] $]^{-}$, were identified as isoquercitrin (quercetin-3-glucoside) and astragalin (kaempferol-3-O-glucoside). And the peak at m/z 301 [M-1] $]^{-}$ was identified as quercetin based on UV spectra and MS fragmentation behaviour.

The presence of an glucoside was supported by loss of $162 \mathrm{u}\left([\mathrm{M}-\mathrm{H}-162]^{-}\right)$from the parent ion $\mathrm{m} / \mathrm{z}$ at $463[\mathrm{M}-1]^{-}$ and $447[\mathrm{M}-1]^{-}$. The anion at $\mathrm{m} / \mathrm{z} 301$ produces the ion at $\mathrm{m} / \mathrm{z} 151$ and 107 through two RDA reactions as depicted in Fig. 3. the C-ring cleavage products ions can be used to confirm the nature of structure of A- and B-rings. The cleavage of bond 3 and 4 of the $C$-ring explains the loss of $\mathrm{CO}(\mathrm{m}=28)$ which had been observed in both isoquercitrin and astragalin. It is interesting that, at the same time, it woudl loss two proton or $\mathrm{H}_{2} \mathrm{O}$, ion $\mathrm{m} / \mathrm{z}$ at 285 and 301 yielded the $[\mathrm{M}-\mathrm{CO}]^{-}$at $\mathrm{m} / \mathrm{z} 257$, $\left[\mathrm{M}-\mathrm{CO}-\mathrm{H}_{2} \mathrm{O}\right]^{-}$at m/z 255, [M-CO-2H] $]^{-}$at m/z 271.

The $\mathrm{C}$-ring cleavage pathway was various, the cleavage of bond 2 and 4 of C-ring explains the m/z 226 ion derived

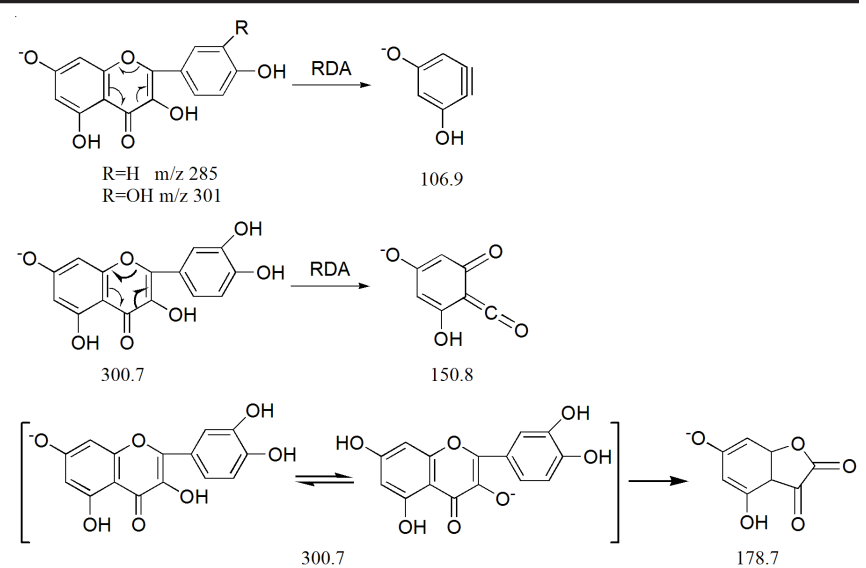

Fig. 3. Proposed MS fragmentation pathway for the [M-H-162]- ions of compounds 8,9 and 10

from $\mathrm{m} / \mathrm{z} 285$ in the spectrum of astragalin. The cleaveage of bond 1 and 2 of C-ring of ion $\mathrm{m} / \mathrm{z} 301$ from the ion 179 in the spectrum of isoquercitrin (Fig. 3).

\section{Conclusion}

Based on the above MS fragmentation rules, ten polyphenolic compounds were identified or characterized from the leaves fo Chinese sweet potato in one LC-MS ${ }^{\mathrm{n}}$ run. In this study, a HPLC-DAD-ESI-MS/MS method was applied and a good example was made for the rapid identification of the constituents in plant extracts. Phenolic compounds are ubiquitous bioactive compounds and a diverse group of secondary metabolites universally present in higher plant, such as caffeic acid and caffeoylquinic acid derivatives. The findings in association with the treatment of the inflammation of the throat, ascites, diarrhea, astriction which were kept for a long time could be extended and do a great help to food technologists and enhance the importance of this food stuff in the human diet.

\section{REFERENCES}

1. K.D. Sarwan, P.S. Hari and D. Seema, Compendium of Transgenic Crop Plants: Sweet Potato, Wiley Online Library (2009).

2. M.S. Islam, M. Yoshimoto, S. Yahara, S. Okuno, K. Ishiguro and O. Yamakawa, J. Agric. Food. Chem., 50, 3718 (2002).

3. M. Takenaka, K. Nanayama, S. Isobe abd M. Murata, Biosci. Biotechnol. Biochem., 70, 172 (2006).

4. W. Zheng and M.N. Clifford, Food Chem., 106, 147 (2008).

5. J.-K. Jung, S.-U. Lee, N. Kozukue, C.E. Levin and M. Friedman, J. Food Compos. Anal., 24, 29 (2011).

6. S. Kaviarasan, A.S. Sivakumar, A. Barik, A. Kunwar, G.H. Naik and K.I. Priyadarsini, J. Food. Biochem., 35, 596 (2011).

7. M.T. Pochapski, E.C. Fosquiera, L.A. Esmerino, E.B. Santos, P.V. Fargo, F.A. Santos and F.C. Groppo, Pharmacog. Mag., 7, 165 (2011).

8. S. Islam, J. Food Sci., 71, R13 (2006).

9. D. Kammerer, R. Carle and A. Schieber, Rapid Commun. Mass Spectrom., 18, 1331 (2004).

10. V. Ossipov, K. Nurmi, J. Loponen, E. Haukioja and K. Pihlaja, J. Chromatogr. A, 721, 59 (1996).

11. E.C. Tatsis, S. Boeren, V. Exarchou, A.N. Troganis, J. Vervoort and I.P. Gerothanassis, Phytochemistry, 68, 383 (2007).

12. A. Ribas-Agustí, M. Gratacós-Cubarsí, S. Sárraga, J.A. García-Regueiro and M. Castellari, Phytochem. Anal., 22, 555 (2011).

13. H. Budzikiewicz, C. Djerassi and D.H. Williams, Mass Spectrometry of Organic Compounds, Holden-Day: San Francisco, p. 219 (1967).

14. M.N. Clifford, S. Knight and N. Kuhnert, J. Agric. Food. Chem., 53, 3821 (2005).

15. Y. Zhang, P. Shi, H. Qu and Y. Cheng, Rapid Commun. Mass Spectrom., 21, 2971 (2007). 